\title{
Synthesis of Unsaturated Amino Alcohols Through Unexpectedly Selective Ru-Catalyzed Cross-Metathesis Reactions
}

Hamid R. Hoveyda, ${ }^{*}$ and Martin Vézina

Tranzyme Pharma Inc., Institut de Pharmacologie de Sherbrooke, 3001, 12e Ave Nord, Sherbrooke, Québec J1H 5N4 Canada

Email : hhoveyda@tranzyme.com

\section{Supplementary Information}

\section{Experimental Section}

\section{General Information}

All the chemicals used herein were purchased from commercial vendors and used as received. Diethyl ether $\left(\mathrm{Et}_{2} \mathrm{O}\right)$ was distilled over sodium/benzophenone and $\mathrm{MeOH}$ was distilled over magnesium/iodine. Anhydrous dichloromethane (DCM), 1,2dichloroethane and DMSO were purchased from EM Science in Sure-Seal ${ }^{\mathrm{TM}}$ bottles. Flash column chromatography ${ }^{1}$ was performed using silica gel 60 (230-400 mesh) (EMD Chemicals). Analytical thin-layer chromatography (TLC) was performed using silica gel $60 \mathrm{~F}_{254}$ pre-coated plates $(0.25 \mathrm{~mm}$ thickness $)$ with a fluorescent indicator from EMD Chemicals. All reactions were conducted using anhydrous solvent(s) under nitrogen atmosphere unless noted otherwise.

NMR spectra were recorded on a Varian Mercury-VX instrument at ambient temperature. The residual solvent protons $\left({ }^{1} \mathrm{H}\right)$ or solvent carbons $\left({ }^{13} \mathrm{C}\right)$ was used as internal standards. ${ }^{1} \mathrm{H}$ NMR data are presented, using the standard abbreviations, as follows: chemical shift $(\delta)$ in ppm (multiplicity, integration, coupling constant(s)). The following abbreviations are used for denoting signal multiplicity: $s=$ singlet, $d=$ doublet, $t$ $=$ triplet, $\mathrm{q}=$ quartet, $\mathrm{br}=$ broad , and $\mathrm{m}=$ multiplet. ${ }^{1} \mathrm{H}-{ }^{1} \mathrm{H}$ COSY spectroscopy was used

(1) Still, W. C.; Kahn, M.; Mitra, A. J. Org. Chem. 1978, 43, 2923-2925. 
to verify ${ }^{1} \mathrm{H}$ NMR assignments (selected data shown for compound $\mathbf{7 b}$ ). High resolution mass spectra were recorded at the Université de Sherbrooke, Mass Spectrometry Service Laborartoy on a ZAB-1F instrument (VG model) using electron impact (EI) ionization technique. Determination of the Ru content in samples was performed using inductively-coupled plasma emission spectroscopy (ICP-ES) at Robertson Microlit Laboratories, Inc. (NJ, USA). The melting point measurements were obtained using a MEL-TEMP 3.0 instrument (Barnstead International) and are uncorrected.

The Ru complexes 2-3 are defined as follows:

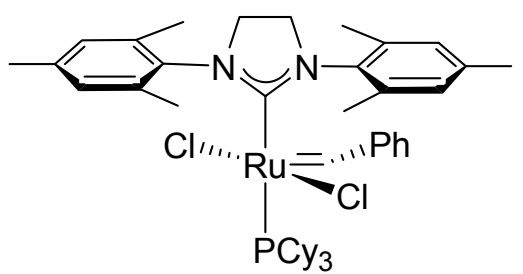

2

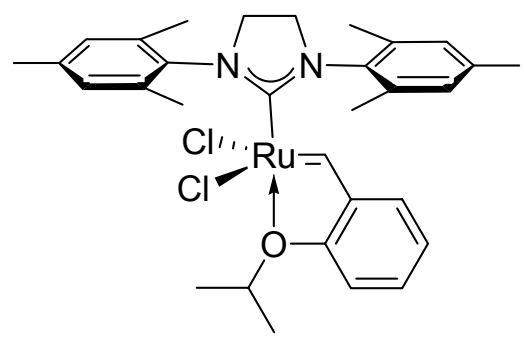

3

\section{Synthetic Procedures}

\section{Representative Procedure for Ru-Catalyzed Cross Metathesis Reaction.}

Compound 7b: 7-Hydroxy-hept-3-enenitrile. In a predried round-bottom flask, ${ }^{2}$ allyl cyanide (7.8 g, $116 \mathrm{mmol}, 2$ equiv) was added to a solution of pen-4-en-1-ol (5 g, 58 mmol, 1 equiv) in DCM $(350 \mathrm{~mL})$ at room temperature. To this solution was added Ru complex $2(2.5 \mathrm{~g}, 3 \mathrm{mmol}, 5 \mathrm{~mol} \%)$ in one portion and the round-bottom flask was fitted with a pre-dried reflux condenser. ${ }^{2}$ This reaction mixture was then heated to reflux (45 ${ }^{\circ} \mathrm{C}$ ) for $2 \mathrm{~h}$ whereupon the reaction allowed to return to room temperature. Ethyl vinyl ether (14 mL, 50 equiv) and DMSO (10 mL, 50 equiv) were then added to the reaction mixture and the solution was agitated for $1 \mathrm{~h}$ in air. After removal of the volatiles under reduced pressure, the resultant dark-colored oil was immediately passed through a short silica gel column $(2 \times 10 \mathrm{~cm})$ using EtOAc/hexanes (3:1) as eluant to remove the bulk of the colored impurity. ${ }^{3}$ The brown oil thus obtained was further purified by silica gel flash column chromatography (EtOAc/hexanes, 1:1 to 3:1 gradient elution). The purified

(2) Oven-dried glassware was brought to room temperature under nitrogen atmosphere.

(3) This was conducted under gravity without applying nitrogen or air pressure. 
product was obtained as a pale yellow-orange oil in $75 \%$ yield $^{4}(5.4 \mathrm{~g})$ as a $6: 1(E: Z)$ mixture. TLC (EtOAc/hexanes, 1:1) $R_{f}=0.20\left(\mathrm{KMnO}_{4}\right) .{ }^{5}{ }^{1} \mathrm{H} \mathrm{NMR}\left(300 \mathrm{MHz}, \mathrm{CDCl}_{3}\right): \delta$ $1.6(\mathrm{~m}, 2 \mathrm{H}), 1.9(\mathrm{~s}, 1 \mathrm{H}), 2.1(\mathrm{~m}, 2 \mathrm{H}), 3.0-3.1(\mathrm{~m}, 2 \mathrm{H}), 3.6(\mathrm{t}, 2 \mathrm{H}, J=6.5 \mathrm{~Hz}), 5.3-5.4(\mathrm{~m}$, $1 \mathrm{H})$, 5.6-5.8 $(\mathrm{m}, 1 \mathrm{H}) .{ }^{13} \mathrm{C} \mathrm{NMR}\left(75 \mathrm{MHz}, \mathrm{CDCl}_{3}\right): \delta 17.7,20.6,23.7,28.6,31.6,31.9$, 61.7, 62.1, 117.8, 117.9, 135.5, 135.7. HRMS: calcd for $\mathrm{C}_{7} \mathrm{H}_{12} \mathrm{NO}(\mathrm{M}+\mathrm{H})^{+}$126.0919, found 126.0922. \%Ru (ICP-ES): 192 ppm. ${ }^{6}$

All the cross-metathesis reactions below were conducted according to the representative procedure described above for compound $\mathbf{7 b}$.

Compound 7a: 6-Hydroxy-hex-2-enenitrile. The following quantity of reagents were used: acrylonitrile (1.23 g, $23.3 \mathrm{mmol}, 2.0$ equiv), pen-4-en-1-ol (1.0 g, $11.6 \mathrm{mmol}, 1.0$ equiv), Ru complex 3 ( $0.363 \mathrm{~g}, 0.58 \mathrm{mmol}, 0.05$ equiv) in $500 \mathrm{~mL}$ DCM. After workup and column chromatography (EtOAc/hexanes, 1:1), the purified product (7a) was obtained as a yellow pale oil in $74 \%$ yield $(954 \mathrm{mg})$ as a $1: 2(E: Z)$ mixture. TLC (EtOAc/hexanes, 1:1) $R_{f}=0.22\left(\mathrm{KMnO}_{4}\right) .{ }^{5}{ }^{1} \mathrm{H}$ NMR $\left(300 \mathrm{MHz}, \mathrm{CDCl}_{3}\right): \delta$ 1.6-1.8 $(\mathrm{m}$, $2 \mathrm{H}), 2.1(\mathrm{~s}, 1 \mathrm{H}), 2.3-2.5(\mathrm{~m}, 2 \mathrm{H}), 3.6-3.7(\mathrm{~m}, 2 \mathrm{H}), 5.3-5.4(\mathrm{~m}, 1 \mathrm{H}), 6.5-6.8(\mathrm{~m}, 1 \mathrm{H}) .{ }^{13} \mathrm{C}$ NMR $\left(75 \mathrm{MHz}, \mathrm{CDCl}_{3}\right): \delta 28.7,30.0,30.1,31.2,61.6,61.8,100.0,100.3,116.2,117.7$, 155.0, 155.8. HRMS: calcd for $\mathrm{C}_{6} \mathrm{H}_{10} \mathrm{NO}(\mathrm{M}+\mathrm{H})^{+} 112.0762$, found 112.0766 .

Compound 7c: 8-Hydroxy-oct-4-enenitrile. The following quantity of reagents were used: pent-4-enenitrile (0.94 g, $11.6 \mathrm{mmol}, 2.0$ equiv), pen-4-en-1-ol $(0.5 \mathrm{~g}, 5.8 \mathrm{mmol}$, 1.0 equiv), Ru complex 2 ( $0.247 \mathrm{~g}, 0.29 \mathrm{mmol}, 0.05$ equiv) in $35 \mathrm{~mL} \mathrm{DCM}$. After workup and column chromatography (EtOAc/hexanes, 1:1), the purified product (7c) was obtained as an orange oil in $72 \%$ yield $(581 \mathrm{mg})$ as a $5: 1(E: Z)$ mixture. $^{7}$ TLC (EtOAc/hexanes, 1:1) $R_{f}=0.26\left(\mathrm{KMnO}_{4}\right) .{ }^{5}{ }^{1} \mathrm{H}$ NMR $\left(300 \mathrm{MHz}, \mathrm{CDCl}_{3}\right): \delta$ 1.6-1.7 (m, $2 \mathrm{H}), 1.7(\mathrm{~s}, 1 \mathrm{H}), 2.1-2.2(\mathrm{~m}, 2 \mathrm{H}), 2.2-2.4(\mathrm{~m}, 4 \mathrm{H}), 3.6(\mathrm{t}, 2 \mathrm{H}, J=6.5 \mathrm{~Hz}), 5.2-5.5(\mathrm{~m}, 1 \mathrm{H})$, 5.5-5.7 (m, $1 \mathrm{H}) .{ }^{13} \mathrm{C}$ NMR $\left(75 \mathrm{MHz}, \mathrm{CDCl}_{3}\right): \delta 17.8,17.9,23.4,23.7,28.5,28.9,32.2$,

(4) This value reflects the unoptimized yield. When this reaction was conducted on a $5.8 \mathrm{mmol}$ scale, $\mathbf{7 b}$ was obtained in $81 \%$ isolated purified yield as indicated in Table 1.

(5) Aqueous potassium permanganate - prepared by mixing $1 \mathrm{~g} \mathrm{KMnO}_{4}$ and $2 \mathrm{~g} \mathrm{~K}_{2} \mathrm{CO}_{3}$ in $100 \mathrm{~mL}$ $\mathrm{H}_{2} \mathrm{O}$ - was used as the revealing agent for the TLC experiment.

(6) With Ru complex 3, using the same workup procedure, the \%Ru $=479 \mathrm{ppm}$ (ICP-ES).

(7) Due to signal overlap in the ${ }^{1} \mathrm{H}$ NMR spectrum, the $E / Z$ ratio was approximated using ${ }^{13} \mathrm{C}$ NMR data. 
32.4, 62.1, 62.4, 119.6, 125.9, 126.5, 133.1, 133.6. HRMS: calcd for $\mathrm{C}_{8} \mathrm{H}_{12} \mathrm{NO}(\mathrm{M}-\mathrm{H})^{+}$ 138.0919, found 138.0917 .

Compound 7d: 5-Hydroxy-pent-3-enenitrile. The following quantity of reagents were used: allyl cyanide $(0.78 \mathrm{~g}, 11.6 \mathrm{mmol}, 2.0$ equiv), allyl alcohol $(0.34 \mathrm{~g}, 5.8 \mathrm{mmol}, 1.0$ equiv), Ru complex 2 ( $0.247 \mathrm{~g}, 0.29 \mathrm{mmol}, 0.05$ equiv) in $35 \mathrm{~mL} \mathrm{DCM}$. After workup and column chromatography (EtOAc/hexanes, 1:1), the purified product $(\mathbf{7 d})$ was obtained as a yellow oil in $38 \%$ yield $(215 \mathrm{mg}$ ) as a $15: 1$ (E:Z) mixture. TLC (EtOAc/hexanes, 1:1) $R_{f}=0.20\left(\mathrm{KMnO}_{4}\right) .{ }^{5}{ }^{1} \mathrm{H} \mathrm{NMR}\left(300 \mathrm{MHz}, \mathrm{CDCl}_{3}\right): \delta 1.6(\mathrm{~s}, 1 \mathrm{H}), 3.1-3.2(\mathrm{~m}, 2 \mathrm{H}), 4.1-4.3$ $(\mathrm{m}, 2 \mathrm{H}), 5.6-5.7(\mathrm{~m}, 1 \mathrm{H}), 6.0-6.1(\mathrm{~m}, 1 \mathrm{H}) .{ }^{13} \mathrm{C} \mathrm{NMR}\left(75 \mathrm{MHz}, \mathrm{CDCl}_{3}\right): \delta 20.4,36.5,60.6$, 62.5, 117.5, 118.7, 134.7. HRMS: calcd for $\mathrm{C}_{5} \mathrm{H}_{8} \mathrm{NO}(\mathrm{M}+\mathrm{H})^{+} 98.0606$, found 98.0609 .

Compound 7e: 6-Hydroxy-hex-3-enenitrile. The following quantity of reagents were used: allyl cyanide $(0.78 \mathrm{~g}, 11.6 \mathrm{mmol}, 2.0$ equiv), but-3-en-1-ol $(0.42 \mathrm{~g}, 5.8 \mathrm{mmol}, 1.0$ equiv), Ru complex 2 ( $0.247 \mathrm{~g}, 0.29 \mathrm{mmol}, 0.05$ equiv) in $35 \mathrm{~mL} \mathrm{DCM}$. After workup and column chromatography (EtOAc/hexanes, 1:1), the purified product (7e) was obtained as a yellow pale oil in $77 \%$ yield $(496 \mathrm{mg})$ as a $3.5: 1$ (E:Z) mixture. TLC (EtOAc/hexanes, 1:1) $R_{f}=0.24\left(\mathrm{KMnO}_{4}\right) .{ }^{5}{ }^{1} \mathrm{H}$ NMR $\left(300 \mathrm{MHz}, \mathrm{CDCl}_{3}\right): \delta 1.6(\mathrm{~s}, 1 \mathrm{H})$, 2.3-2.4 (m, 2H), 3.1-3.2 (m, 2H), 3.7-3.7 (m, 2H), 5.4-5.6 (m, 1H), 5.7-5.9 (m, $1 \mathrm{H}) .{ }^{13} \mathrm{C}$ NMR $\left(75 \mathrm{MHz}, \mathrm{CDCl}_{3}\right): \delta 16.0,20.7,30.9,35.6,61.5,61.7,117.9,118.4,119.6,120.1$, 132.4, 132.6. HRMS: calcd for $\mathrm{C}_{6} \mathrm{H}_{10} \mathrm{NO}(\mathrm{M}+\mathrm{H})^{+} 112.0762$, found 112.0765 .

Compound 9: 7-Trityloxy-hept-3-enenitrile. The following quantity of reagents were used: allyl cyanide ( $0.78 \mathrm{~g}, 11.6 \mathrm{mmol}, 2.0$ equiv), 8 ( $1.90 \mathrm{~g}, 5.8 \mathrm{mmol}, 1.0$ equiv), Ru complex 2 ( $0.247 \mathrm{~g}, 0.29 \mathrm{mmol}, 0.05$ equiv) in $35 \mathrm{~mL}$ DCM. After workup and column chromatography (EtOAc/hexanes, 1:9), the purified product (9) was obtained as a brown solid in $23 \%$ yield $(485 \mathrm{mg})$ as a $2.5: 1(E: Z)$ mixture. TLC (EtOAc/hexanes, 1:3) $R_{f}=$ $0.60\left(\mathrm{UV}\right.$ and $\left.\mathrm{KMnO}_{4}\right) .{ }^{5}{ }^{1} \mathrm{H}$ NMR $\left(300 \mathrm{MHz}, \mathrm{CDCl}_{3}\right): \delta$ 1.6-1.8 (m, 2H), 2.1-2.2 (m, 2H), 2.9-3.0 (m, 2H), 3.0-3.1 (m, 2H), 5.2-5.4 (m, 1H), 5.5-5.8 (m, 1H), 7.2-7.3 (m, 9H), 7.4$7.5(\mathrm{~m}, 6 \mathrm{H}) .{ }^{13} \mathrm{C} \mathrm{NMR}\left(75 \mathrm{MHz}, \mathrm{CDCl}_{3}\right): \delta 15.7,20.6,24.3,29.2,29.4,62.7,86.6,117.6$, 117.7, 118.1, 127.1, 128.0, 128.9, 135.5, 135.9, 144.6. HRMS: calcd for $\mathrm{C}_{26} \mathrm{H}_{25} \mathrm{NO}(\mathrm{M})^{+}$ 367.1936, found 367.1930 . Melting point: $80-82^{\circ} \mathrm{C}$.

Compound 11: 2-Hydroxy-hex-3-enenitrile. The following quantity of reagents were used: allyl cyanide $(0.78 \mathrm{~g}, 11.6 \mathrm{mmol}, 2.0$ equiv), but-3-en-2-ol $(0.42 \mathrm{~g}, 5.8 \mathrm{mmol}, 1.0$ equiv), Ru complex 2 ( $0.247 \mathrm{~g}, 0.29 \mathrm{mmol}, 0.05$ equiv) in $35 \mathrm{~mL}$ DCM. After workup and 
column chromatography (EtOAc/hexanes, 1:1), the purified product (11) was obtained as a yellow pale oil in $21 \%$ yield $(135 \mathrm{mg})$ as a $5: 1(E: Z)$ mixture. TLC (EtOAc/hexanes, 1:1) $R_{f}=0.27\left(\mathrm{KMnO}_{4}\right){ }^{5} \quad{ }^{1} \mathrm{H}$ NMR $\left(300 \mathrm{MHz} \mathrm{CDCl}_{3}\right): \delta 1.3(\mathrm{~d}, 3 \mathrm{H}, J=6.5 \mathrm{~Hz}), 1.7(\mathrm{~s}$, $1 \mathrm{H}), 3.1-3.3(\mathrm{~m}, 2 \mathrm{H}), 4.3-4.6(\mathrm{~m}, 1 \mathrm{H}), 5.4-5.64(\mathrm{~m}, 1 \mathrm{H}), 5.67-6.0(\mathrm{~m}, 1 \mathrm{H}) .{ }^{13} \mathrm{C}$ NMR $(75$ $\left.\mathrm{MHz}, \mathrm{CDCl}_{3}\right): \delta 16.1,20.1,23.3,23.5,63.9,67.7,117.2,117.8,139.4,139.6$. HRMS: calcd for $\mathrm{C}_{6} \mathrm{H}_{8} \mathrm{NO}(\mathrm{M}-\mathrm{H})^{+} 110.0606$, found 110.0602 .

Compound 14: 4-[1,3]-Dioxolane-2-yl-but-3-enenitrile. The following quantity of reagents were used: allyl cyanide $(0.78 \mathrm{~g}, 11.6 \mathrm{mmol}, 2.0$ equiv), 2-vinyl-1,3-dioxolane (0.58 g, $5.8 \mathrm{mmol}, 1.0$ equiv), Ru complex 2 (0.247 g, $0.29 \mathrm{mmol}, 0.05$ equiv) in $35 \mathrm{~mL}$ DCM. After workup and column chromatography (EtOAc/hexanes, 1:1), the purified product (14) was obtained as an orange oil in $26 \%$ yield $(208 \mathrm{mg})$ as a $2.5: 1$ (E:Z) mixture. TLC (EtOAc/hexanes, 1:1) $R_{f}=0.44\left(\mathrm{KMnO}_{4}\right) .{ }^{5}{ }^{1} \mathrm{H} \mathrm{NMR}\left(300 \mathrm{MHz}, \mathrm{CDCl}_{3}\right): \delta$ 3.1-3.2 (m, 2H), 3.9-4.0 (m, 4H), 5.28-5.32 (m, 1H), 5.8-5.9 (m, 2H). ${ }^{13} \mathrm{C} N M R(75 \mathrm{MHz}$, $\left.\mathrm{CDCl}_{3}\right): \delta 20.3,20.4,65.2,65.3,102.4,102.5,116.7,116.8,123.3,123.5,131.6,132.0$. HRMS: calcd for $\mathrm{C}_{7} \mathrm{H}_{8} \mathrm{NO}_{2}(\mathrm{M}-\mathrm{H})^{+} 138.0555$, found 138.0550 .

Compound 16: 4-Phenyl-but-3-enenitrile. The following quantity of reagents were used: allyl cyanide ( $0.78 \mathrm{~g}, 11.6 \mathrm{mmol}, 2.0$ equiv), styrene $(0.60 \mathrm{~g}, 5.8 \mathrm{mmol}, 1.0$ equiv), Ru complex 2 (0.247 g, $0.29 \mathrm{mmol}, 0.05$ equiv) in $35 \mathrm{~mL}$ DCM. After workup and column chromatography (EtOAc/hexanes, 1:4), the purified product (16) was obtained as a brown pale solid in $10 \%$ yield $(83 \mathrm{mg})$ as the $E$ isomer. TLC (EtOAc/hexanes, 1:4) $R_{f}=$ $0.39\left(\mathrm{KMnO}_{4}\right) .{ }^{5}{ }^{1} \mathrm{H} \mathrm{NMR}\left(300 \mathrm{MHz}, \mathrm{CDCl}_{3}\right): \delta 3.3(\mathrm{dd}, 2 \mathrm{H}, J=5.9,1.7 \mathrm{~Hz}), 6.1(\mathrm{dt}, 1 \mathrm{H}, J$ $=15.8,5.6 \mathrm{~Hz}), 6.7(\mathrm{~d}, 1 \mathrm{H}, J=15.8 \mathrm{~Hz}), 7.2-7.4(\mathrm{~m}, 5 \mathrm{H}) .{ }^{13} \mathrm{C} \mathrm{NMR}\left(75 \mathrm{MHz}, \mathrm{CDCl}_{3}\right): \delta$ 21.0, 117.0, 117.6, 126.7, 128.5, 129.0, 134.9, 135.9. HRMS: calcd for $\mathrm{C}_{10} \mathrm{H}_{9} \mathrm{~N}(\mathrm{M})^{+}$ 143.0735, found 143.0731 . Melting point: $56-58{ }^{\circ} \mathrm{C}$.

Compound 17: 8-Trityloxy-oct-4-en-1-ol. The following quantity of reagents were used: 8 (3.80 g, 11.6 mmol, 2.0 equiv), pent-4-en-1-ol (0.50 g, $5.8 \mathrm{mmol}, 1.0$ equiv), Ru complex 2 (0.247 g, $0.29 \mathrm{mmol}, 0.05$ equiv) in $35 \mathrm{~mL}$ DCM. After workup and column chromatography (EtOAc/hexanes, 1:3), the purified product (17) was obtained as a brown pale oil in $60 \%$ yield $(1.35 \mathrm{~g})$ as a $2.5: 1$ (E:Z) mixture. TLC (EtOAc/hexanes, 1:3) $R_{f}=0.20\left(\mathrm{KMnO}_{4}\right) .^{5}{ }^{1} \mathrm{H}$ NMR $\left(300 \mathrm{MHz}, \mathrm{CDCl}_{3}\right): \delta 1.2\left(\mathrm{br} \mathrm{s},{ }^{8} 1 \mathrm{H}\right), 1.5-1.7(\mathrm{~m}, 4 \mathrm{H}), 2.0-$ $2.4(\mathrm{~m}, 4 \mathrm{H}), 3.0-3.1(\mathrm{~m}, 2 \mathrm{H}), 3.5-3.7(\mathrm{~m}, 2 \mathrm{H}), 5.3-5.5(\mathrm{~m}, 2 \mathrm{H}), 7.2-7.3(\mathrm{~m}, 9 \mathrm{H}), 7.4-7.5$

(8) The triplet signals of residual EtOAc partially overlap this broad singlet signal. 
(m, 6H). ${ }^{13} \mathrm{C}$ NMR $\left(75 \mathrm{MHz}, \mathrm{CDCl}_{3}\right): \delta 29.1,29.5,30.1,32.6,36.2,62.7,63.0,63.1$, 86.5, 127.0, 127.1, 127.9, 128.9, 130.0, 130.7, 144.6, 144.7. HRMS: calcd for $\mathrm{C}_{27} \mathrm{H}_{30} \mathrm{O}_{2}$ $(\mathrm{M})^{+}$386.2246, found 386.2251.

\section{Representative Procedure for the One-Pot Nitrile Reduction/Amine Protection Reaction.}

Compound 18a: (7-Hydroxy-hept-3-enyl)-carbamic acid 9H-fluoren-9-ylmethyl ester. A solution of $7 \mathbf{b}$ (2.6 g, 21 mmol, 1 equiv) in $\mathrm{Et}_{2} \mathrm{O}(200 \mathrm{~mL})$ was added into a predried ${ }^{2}$ three neck round-bottom flask. The reaction flask was subjected to three rapid cycles of vacuum/nitrogen purge and the reaction mixture was then cooled to $-78{ }^{\circ} \mathrm{C}$. Subsequently, DIBAI-H (1.0 M in DCM; $85 \mathrm{~mL}, 84 \mathrm{mmol}, 4.0$ equiv) was slowly added over $1 \mathrm{~h}$, manually using a syringe. The resulting solution was stirred at $-78{ }^{\circ} \mathrm{C}$ for $2 \mathrm{~h}$. TLC was used to determine the extent of $\mathbf{7 b}$ remaining, thus establishing the extent of progress of reaction. $^{9}$ If the reaction was found to be incomplete, an additional equivalent of DIBAI-H was introduced into the reaction mixture followed by stirring for an additional $1 \mathrm{~h}$ at $-78{ }^{\circ} \mathrm{C}$. Once $7 \mathrm{~b}$ was fully consumed (TLC), Fmoc-OSu $(29 \mathrm{~g}, 85 \mathrm{mmol}$, 4 equiv) was added at $-78{ }^{\circ} \mathrm{C}$ in one portion and within 10 minutes a solution of $\mathrm{NaBH}_{4}$ $\left(8 \mathrm{~g}, 210 \mathrm{mmol}, 10\right.$ equiv) in $\mathrm{MeOH}(200 \mathrm{~mL})^{10}$ was introduced into the reaction mixture in one portion. After 15 minutes, the dry ice/acetone bath was replaced with an ice bath, thus allowing the reaction mixture to gradually warm to $0{ }^{\circ} \mathrm{C}$. The reaction was stirred at $0{ }^{\circ} \mathrm{C}$ for $1 \mathrm{~h}$ before it was allowed to attain room temperature. Thereafter $\mathrm{NaHCO}_{3}(2.1$ $\mathrm{g}, 25 \mathrm{mmol}, 1.2$ equiv) was added to the reaction mixture and the resultant mixture was

(9) TLC (EtOAc/hexanes, 1:1 with $\left.2 \% \mathrm{Et}_{3} \mathrm{~N}\right) R_{f}=0.31\left(\mathrm{KMnO}_{4}\right)^{5}$

(10) The methanolic sodium borohydride was prepared immediately prior to use in predried glassware under an inert atmosphere. Upon addition of sodium borohydride to methanol, mild bubbling was observed (hydrogen gas evolution).

A variant to the above procedure was initially attempted wherein $\mathrm{NaBH}_{4}$ was introduced as a solid followed by addition of $\mathrm{MeOH}$ (see: Gallagher T. F.; Adams, J. L. J. Org. Chem. 1992, 57, 33473353). Using this procedure, the secondary amine dimeric side-product formation was still observed. Thus, we resorted to a pre-made solution of methanolic $\mathrm{NaBH}_{4}$, as aforementioned, which proved to be significantly more effective in suppressing the dimer side-reaction, presumably through a more rapid reduction of the nitrile intermediate given that $\mathrm{NaBH}_{4}$ does not require additional time to dissolve in the reaction medium.

As a further practical remark, we wish to note that when $\mathrm{NaBH}_{4}$ was added as a solid (followed by addition of $\mathrm{MeOH}$ ), vigorous bubbling occurred while warming the reaction mixture to room temperature - which required extreme caution and adequate head space in reaction container. In contrast, the procedure described above was easier to handle and more controlled, since the bubbling observed when preparing the methanolic $\mathrm{NaBH}_{4}$ was a much less vigorous event, and upon warming the reaction mixture to room temperature no further precautions were found to be necessary. 
stirred overnight at room temperature. For workup, $\mathrm{Et}_{2} \mathrm{O}(500 \mathrm{~mL})$ and saturated aqueous $\mathrm{NaHCO}_{3}$ solution $(500 \mathrm{~mL}$ ) were introduced into the reaction mixture and the aqueous phase was extracted further with $\mathrm{Et}_{2} \mathrm{O}(3 \times 300 \mathrm{~mL})$. The organic extracts were then combined, washed with brine $(1 \times 500 \mathrm{~mL})$, dried $\left(\mathrm{MgSO}_{4}\right)$, filtered and the volatiles removed under reduced pressure. The crude product thus obtained was then subjected to silica gel flash column chromatography (EtOAc/hexanes: $1: 1$ to $3: 1$ gradient elution). The title compound was obtained as a white solid in $97 \%$ yield $(7.1 \mathrm{~g})$. TLC (EtOAc/hexanes, 1:1) $R_{f}=0.25\left(\mathrm{KMnO}_{4}\right) .{ }^{5}{ }^{1} \mathrm{H} \mathrm{NMR}\left(300 \mathrm{MHz}, \mathrm{CDCl}_{3}\right): \delta 1.5-1.7(\mathrm{~m}, 3 \mathrm{H})$, 2.1-2.3 (m, 4H), $3.2(\mathrm{br} \mathrm{s}, 2 \mathrm{H}), 3.6(\mathrm{t}, 2 \mathrm{H}, J=6.3 \mathrm{~Hz}), 4.2(\mathrm{t}, 1 \mathrm{H}, J=6.6 \mathrm{~Hz}), 4.4(\mathrm{~d}, 2 \mathrm{H}$, $J=6.7 \mathrm{~Hz}), 4.9(\mathrm{br} \mathrm{s}, 1 \mathrm{H}), 5.3-5.6(\mathrm{~m}, 2 \mathrm{H}), 7.2-7.3(\mathrm{~m}, 2 \mathrm{H}), 7.4-7.5(\mathrm{~m}, 2 \mathrm{H}), 7.6(\mathrm{~d}, 2 \mathrm{H}, J$ $=7.3 \mathrm{~Hz}$ ), 7.8 (d, $2 \mathrm{H}, J=7.3 \mathrm{~Hz}) .{ }^{13} \mathrm{C} \mathrm{NMR}\left(75 \mathrm{MHz}, \mathrm{CDCl}_{3}\right): \delta 23.6,27.8,29.3,32.1$, 32.4 , 33.2, 40.8, 47.5, 62.6, 66.6, 120.2, 125.2, 127.2, 127.3, 127.9, 133.1, 141.5, 144.2, 156.7. HRMS: calcd for $\mathrm{C}_{22} \mathrm{H}_{24} \mathrm{NO}_{3}(\mathrm{M}+\mathrm{H})^{+} 352.1913$, found 352.1920. Melting point: $94-96{ }^{\circ} \mathrm{C}$.

Compound 18b. 7-Hydroxy-hept-3-enyl)-carbamic acid tert-butyl ester. The same procedure as that described above for 18a was used with the following exceptions: $\mathrm{Boc}_{2} \mathrm{O}$ was used instead of Fmoc-OSu and the reaction was performed on a $100 \mathrm{mg}(0.8$ $\mathrm{mmol}$ ) scale; other reagent stoichiometries were modified accordingly. After workup and silica gel flash column chromatography (EtOAc/hexanes, 1:1), the purified product was obtained as a colorless oil in $78 \%$ yield $\left(143 \mathrm{mg}\right.$ ). TLC (EtOAc/hexanes, 1:1) $R_{f}=0.32$ $\left(\mathrm{KMnO}_{4}\right) .{ }^{5}{ }^{1} \mathrm{H} \mathrm{NMR}\left(300 \mathrm{MHz}, \mathrm{CDCl}_{3}\right): \delta 1.4(\mathrm{~s}, 9 \mathrm{H}), 1.5-1.7(\mathrm{~m}, 2 \mathrm{H}), 1.8(\mathrm{br} \mathrm{s}, 1 \mathrm{H}), 2.0-$ $2.2(\mathrm{~m}, 4 \mathrm{H}), 3.1(\mathrm{t}, 2 \mathrm{H}, J=6.7 \mathrm{~Hz}), 3.6(\mathrm{t}, 3 \mathrm{H}, J=6.3 \mathrm{~Hz}), 4.5(\mathrm{br} \mathrm{s}, 1 \mathrm{H}), 5.3-5.5(\mathrm{~m}, 2 \mathrm{H})$. ${ }^{13} \mathrm{C}$ NMR $\left(75 \mathrm{MHz}, \mathrm{CDCl}_{3}\right): \delta 18.3,22.8,23.3,23.4,23.9,27.0,27.1,28.0,35.1,56.6$, 57.2, 72.2, 74.1, 121.6, 122.2, 126.7, 127.4, 150.9. HRMS: calcd for $\mathrm{C}_{12} \mathrm{H}_{25} \mathrm{NO}_{3}(\mathrm{M}+\mathrm{H})^{+}$ 230.1756 , found 230.1751 .

Compound 8: 5-Trityloxy-pent-1-ene. To a solution of triphenylmethane chloride $(6.9 \mathrm{~g}$, $25 \mathrm{mmol}, 1$ equiv) in DCM $(300 \mathrm{~mL})$ at $0{ }^{\circ} \mathrm{C}$ was added pent-4-en-1-ol $(3.2 \mathrm{~g}, 37.5 \mathrm{mmol}$, 1.5 equiv) and triethylamine $(7.6 \mathrm{~g}, 75 \mathrm{mmol}, 3$ equiv). The resulting solution was allowed to warm to room temperature and stirred for an additional $3 \mathrm{~h}$. The organic phase was washed with saturated aqueous $\mathrm{NH}_{4} \mathrm{Cl}$ solution $(3 \times 200 \mathrm{~mL})$, water (1x 200 $\mathrm{mL})$, brine $(1 \mathrm{x} 200 \mathrm{~mL})$, dried $\left(\mathrm{MgSO}_{4}\right)$, filtered and the solvent was removed under reduced pressure. The crude oil thus obtained was then subjected to silica gel flash column chromatography (EtOAc/hexanes: 1:24). The title compound was obtained as a 
colorless oil in $75 \%$ yield $(6.1 \mathrm{~g})$. TLC (EtOAc/hexanes, 1:9) $R_{f}=0.60\left(\mathrm{KMnO}_{4}\right) \cdot{ }^{5}{ }^{1} \mathrm{H}$ NMR (300 MHz, CDCl $\left.{ }_{3}\right) \delta$ 1.7-1.9 (m, 2H), 1.9-2.3 (m, 2H), 3.1 (t, 2H, J = 6.4 Hz), 4.9$5.1(\mathrm{~m}, 2 \mathrm{H}), 5.7-5.9(\mathrm{~m}, 1 \mathrm{H}), 7.2-7.4(\mathrm{~m}, 9 \mathrm{H}), 7.5-7.6(\mathrm{~m}, 6 \mathrm{H}) .{ }^{13} \mathrm{C} N M R(75 \mathrm{MHz}$, $\left.\mathrm{CDCl}_{3}\right) \delta 29.5,30.8,63.3,86.6,114.8,127.1,128.0,129.0,138.9,144.7$; HRMS calcd for $\mathrm{C}_{24} \mathrm{H}_{24} \mathrm{O}(\mathrm{M})^{+} 328.1827$, found 328.1831 . 


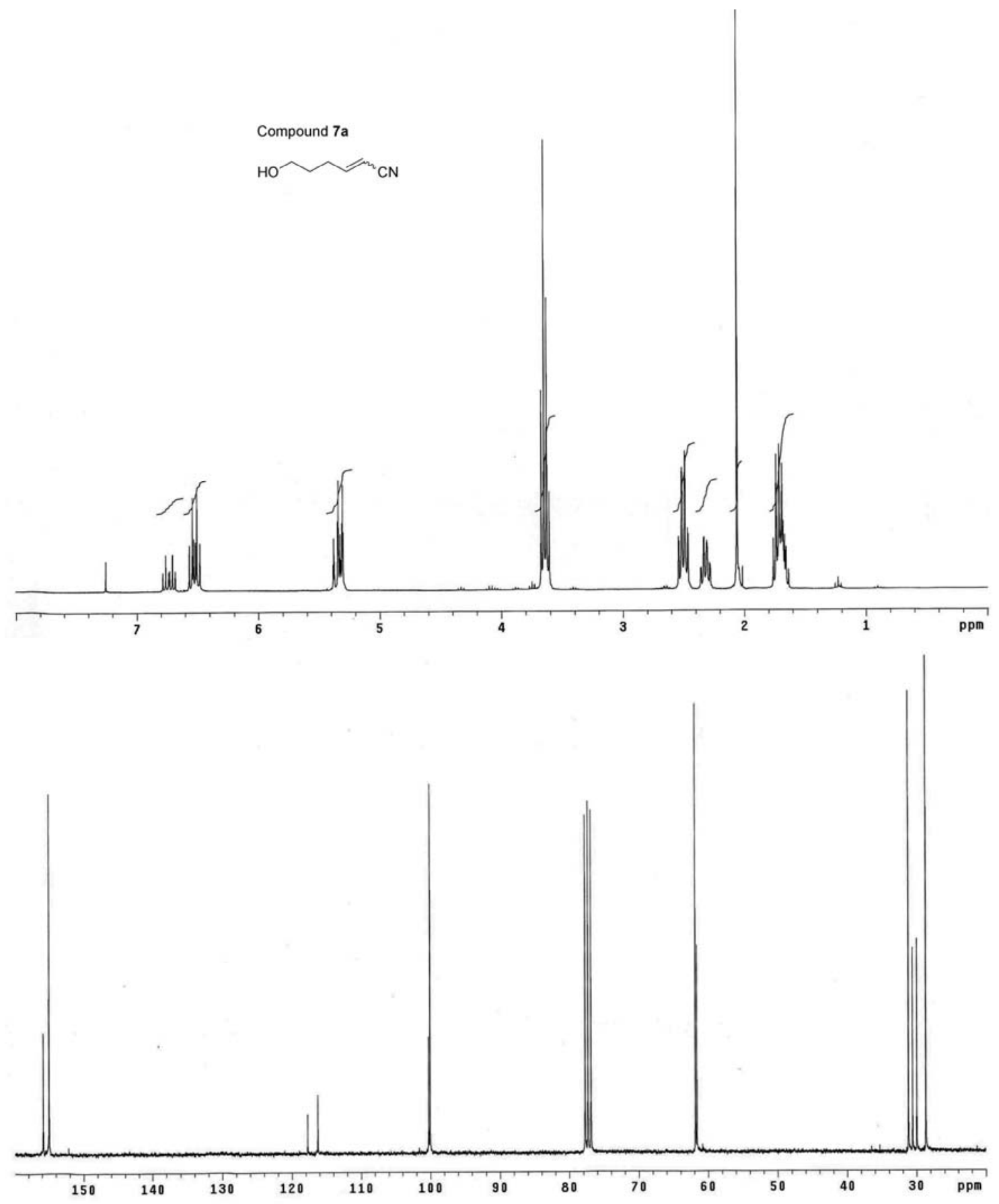



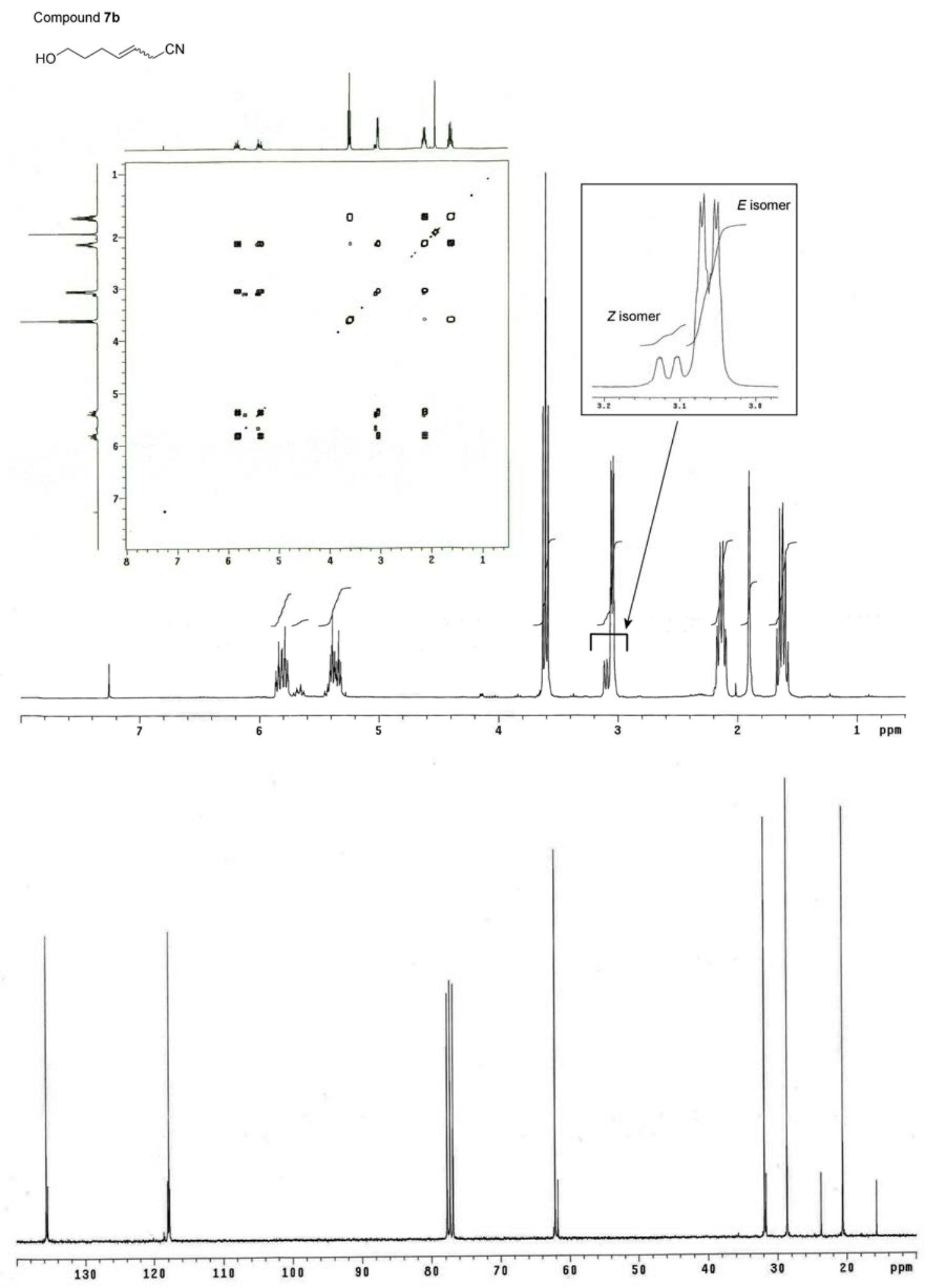

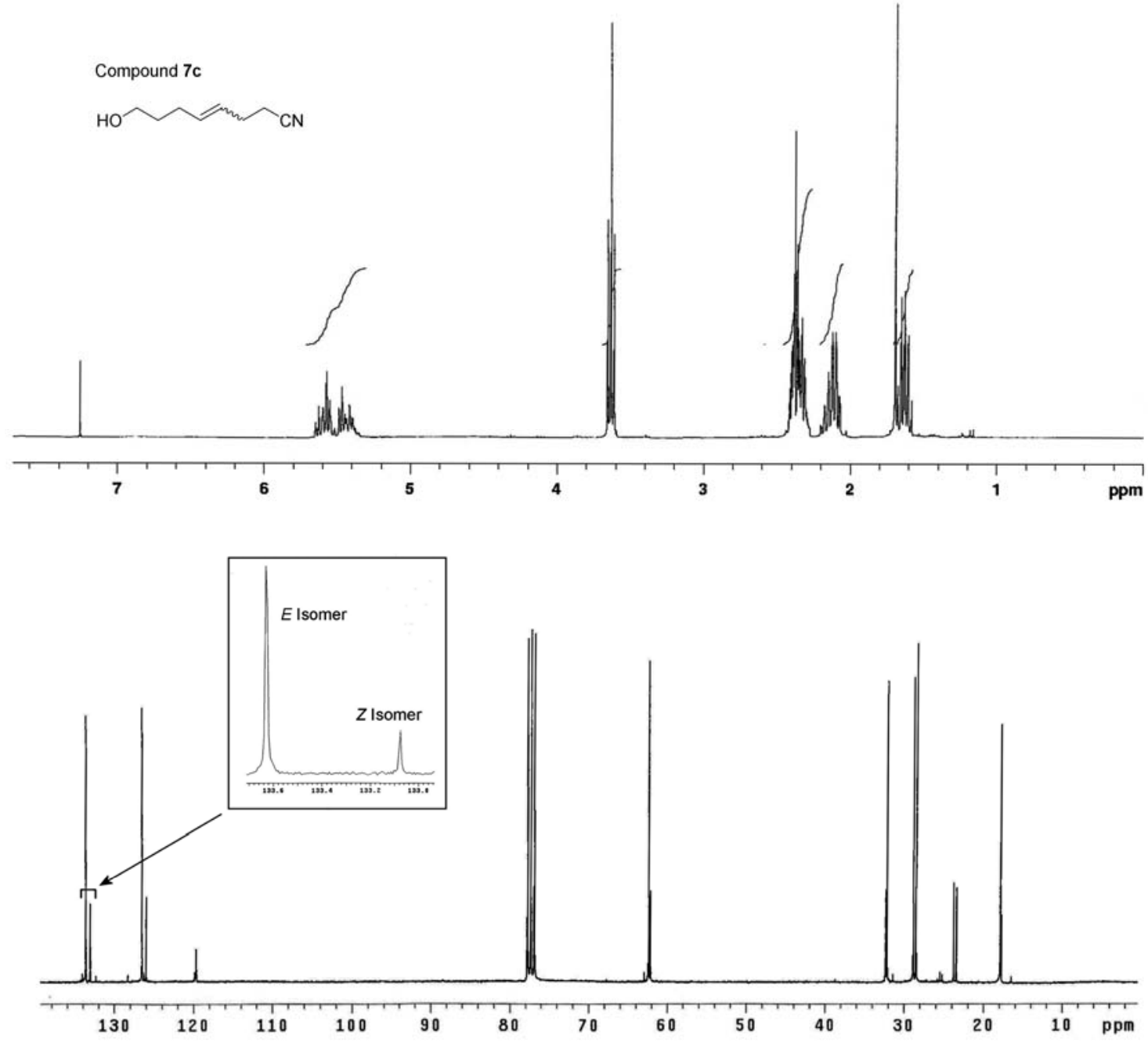


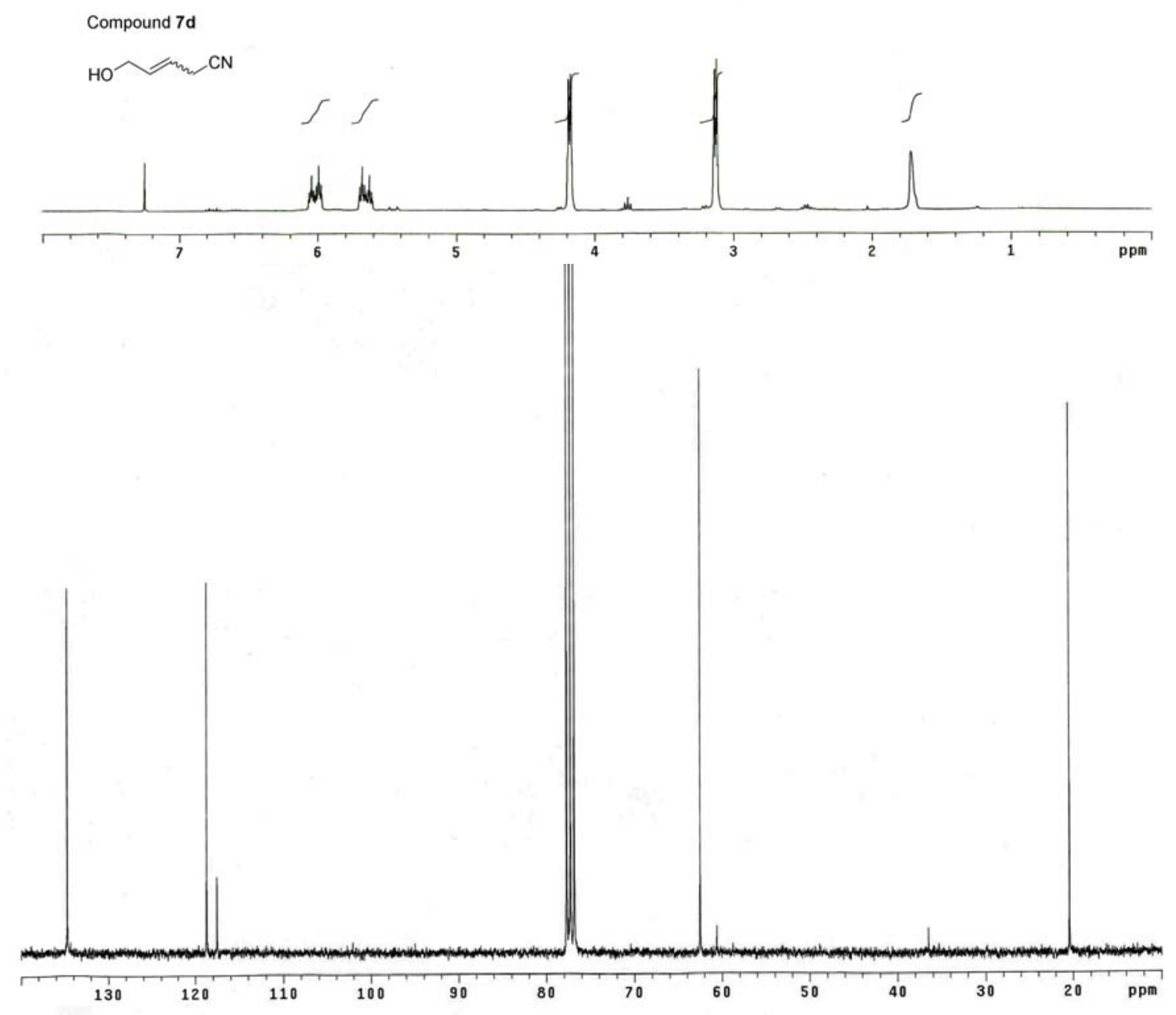




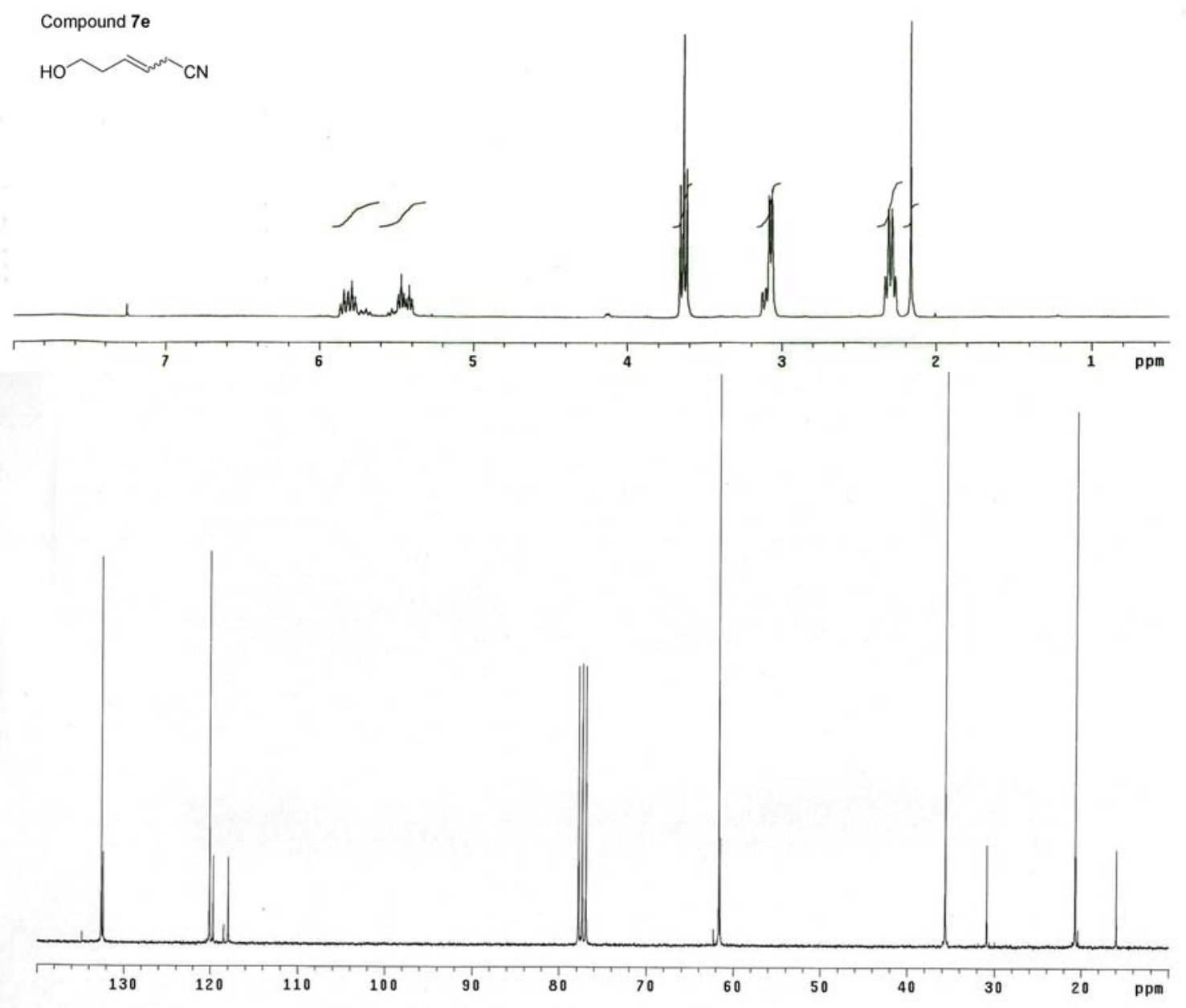




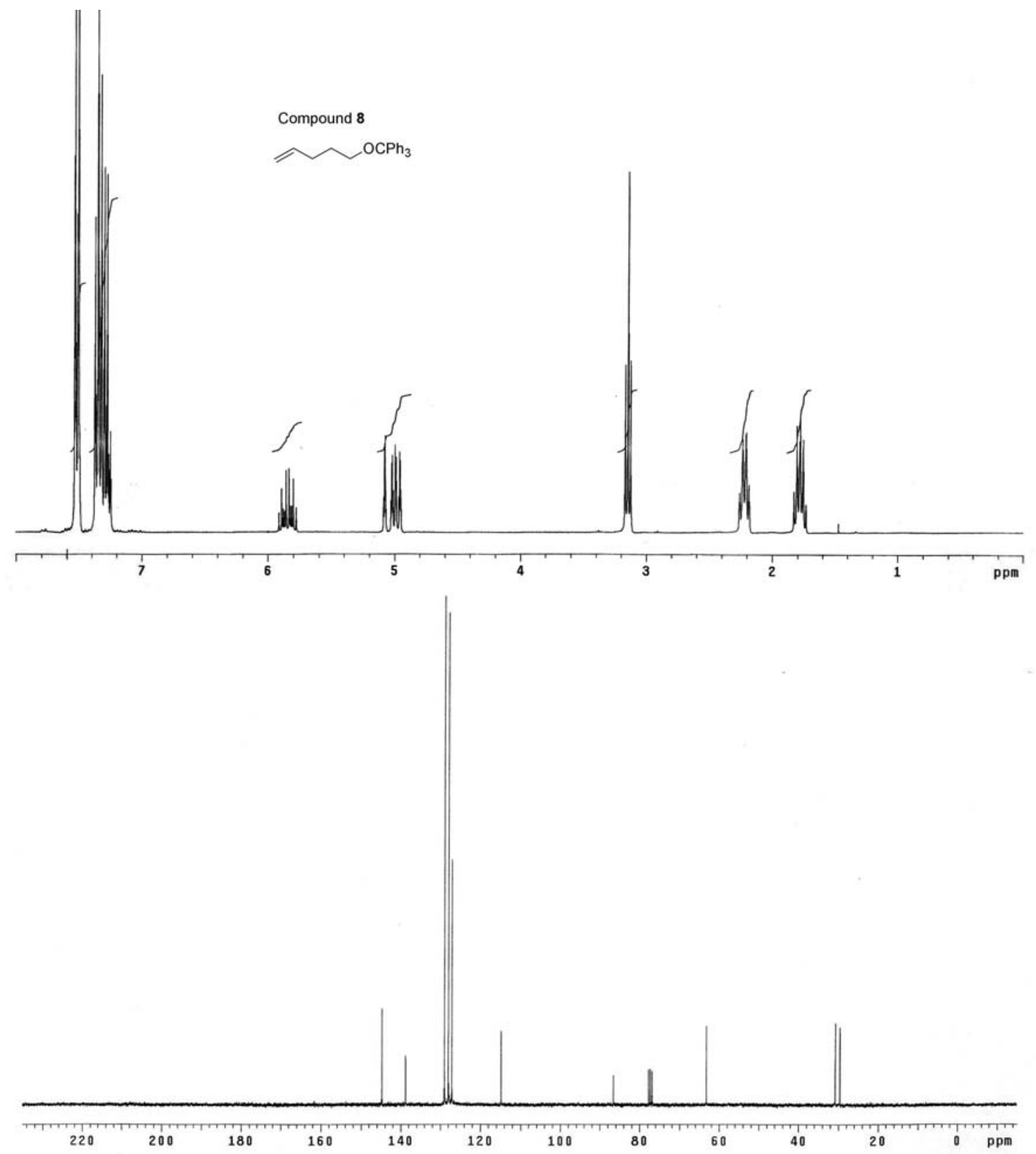



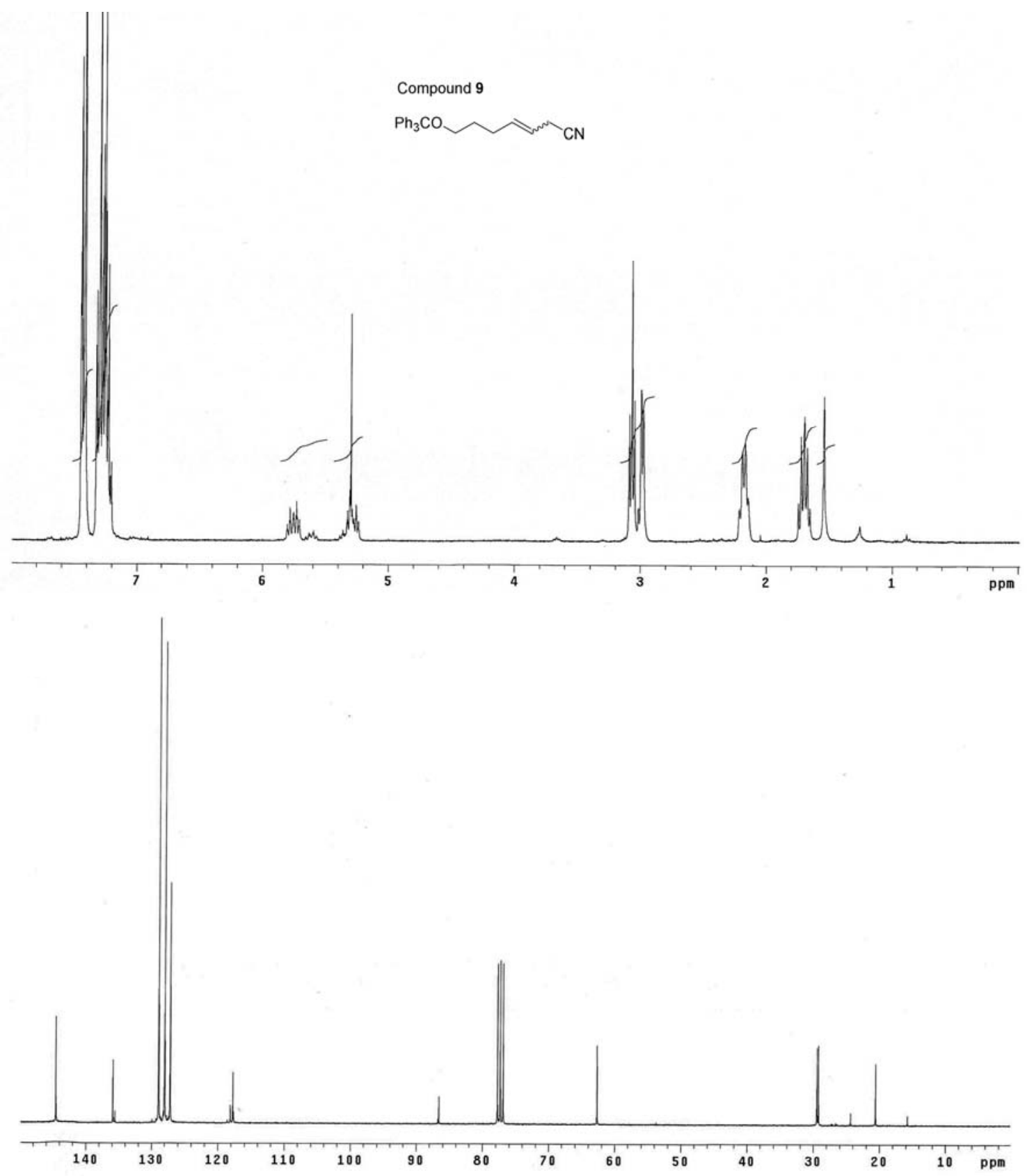


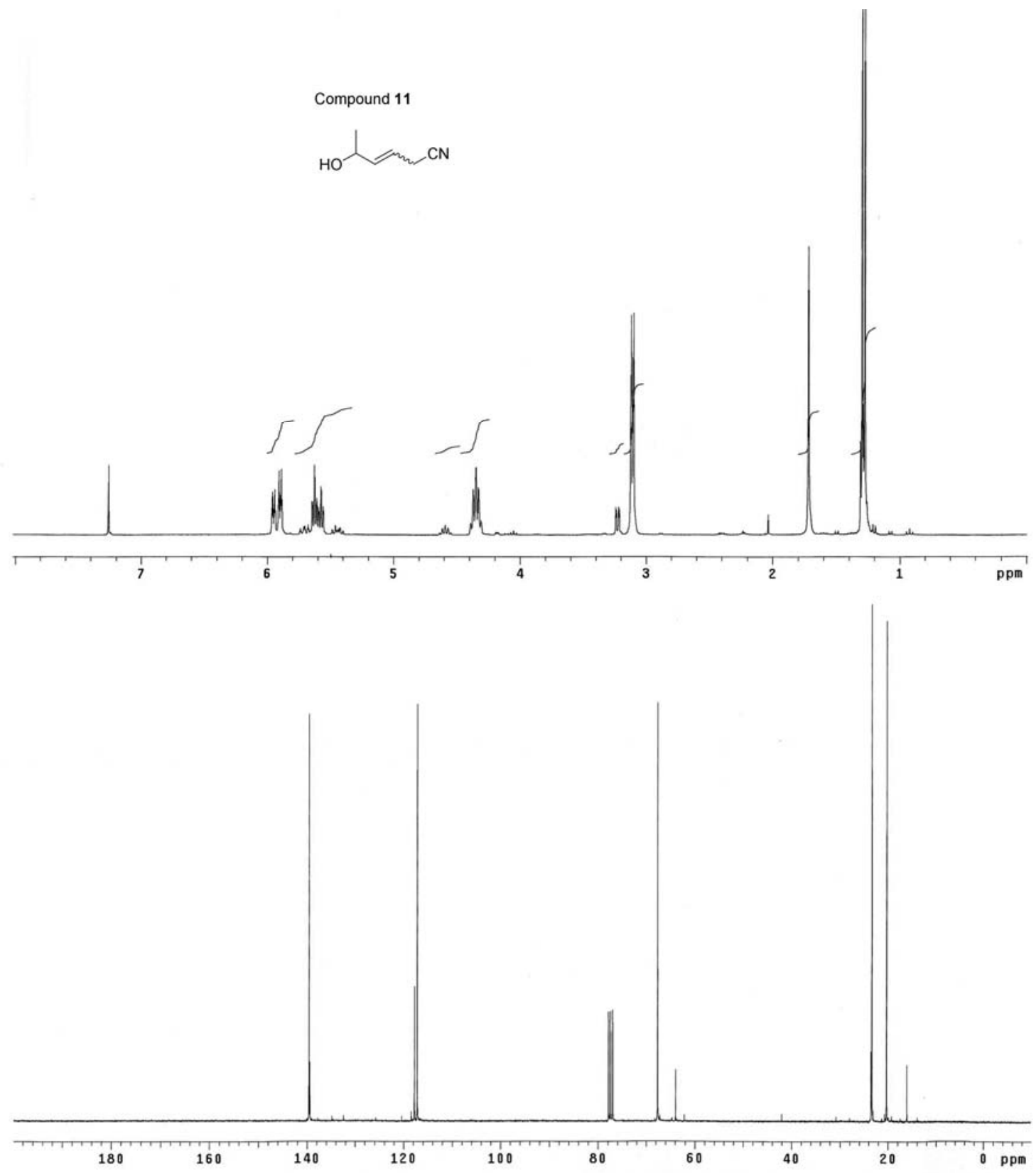




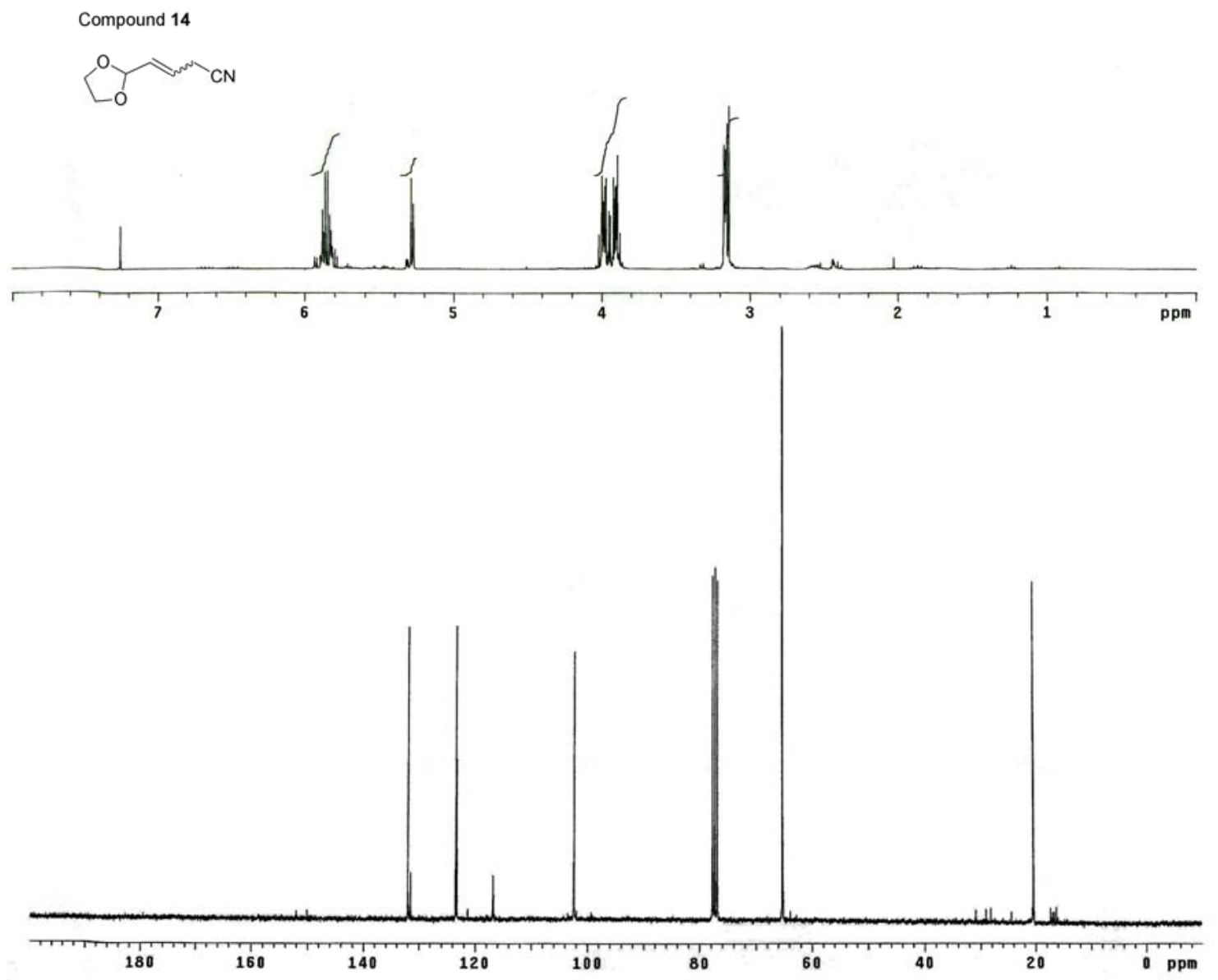



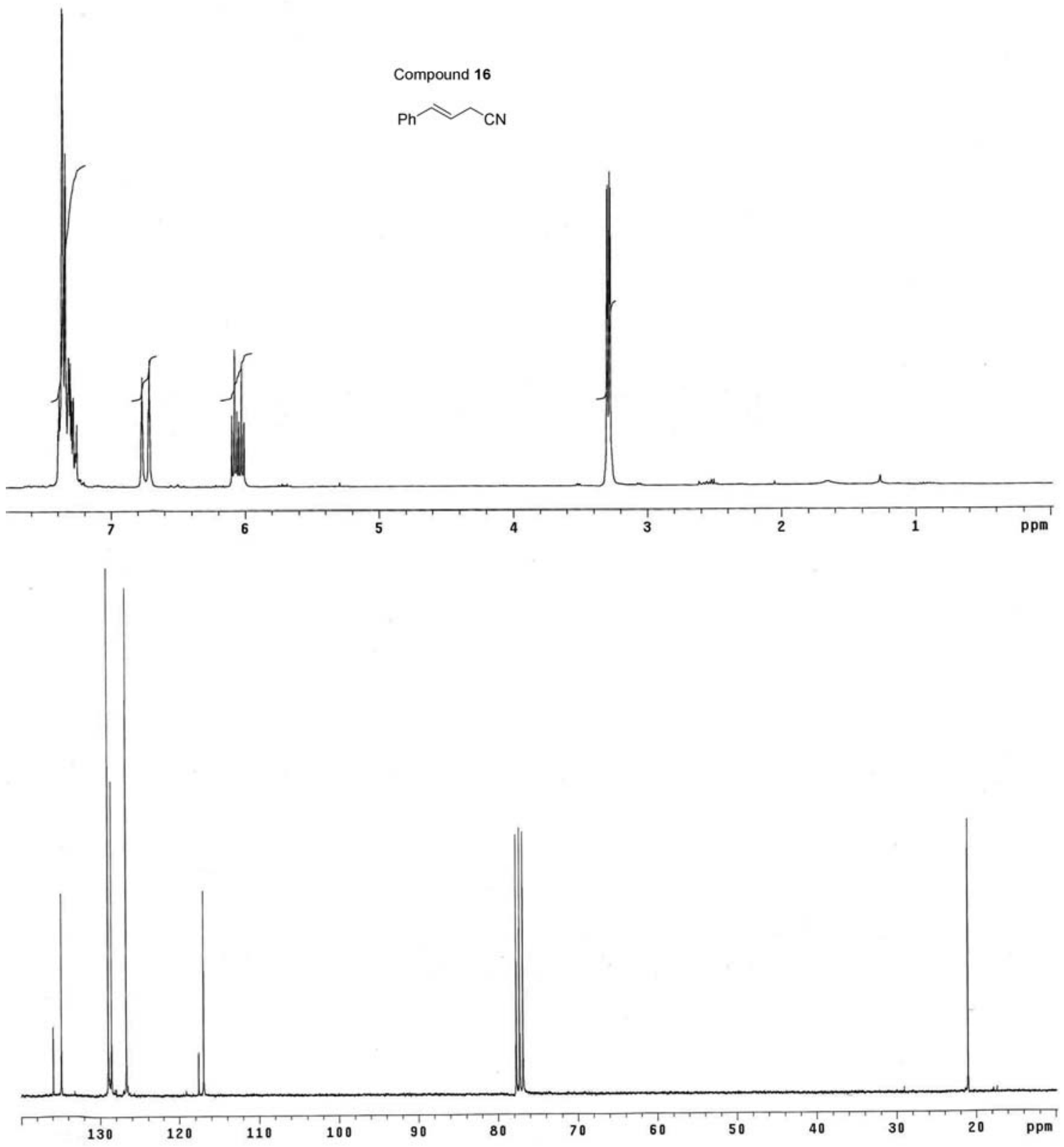


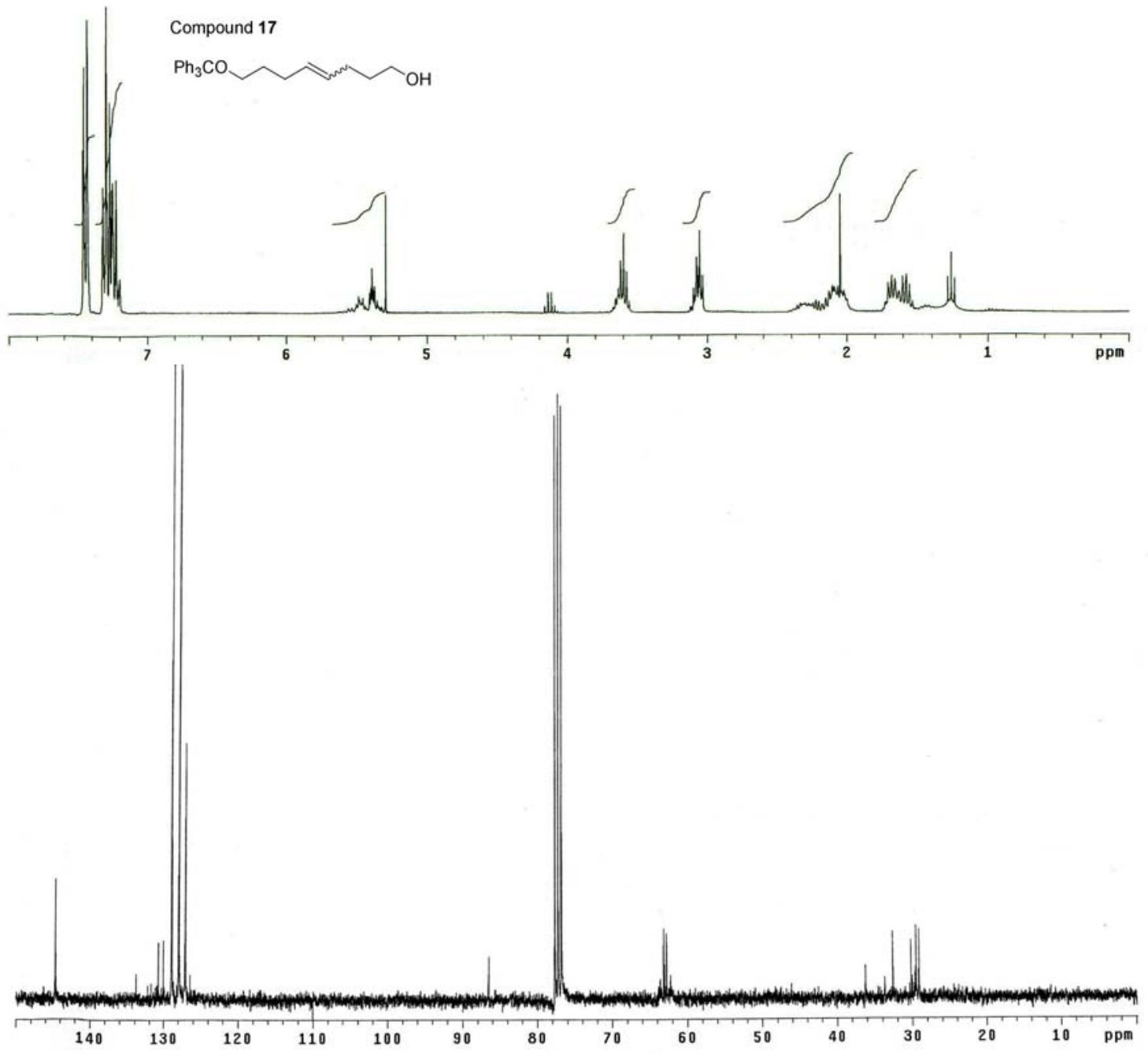



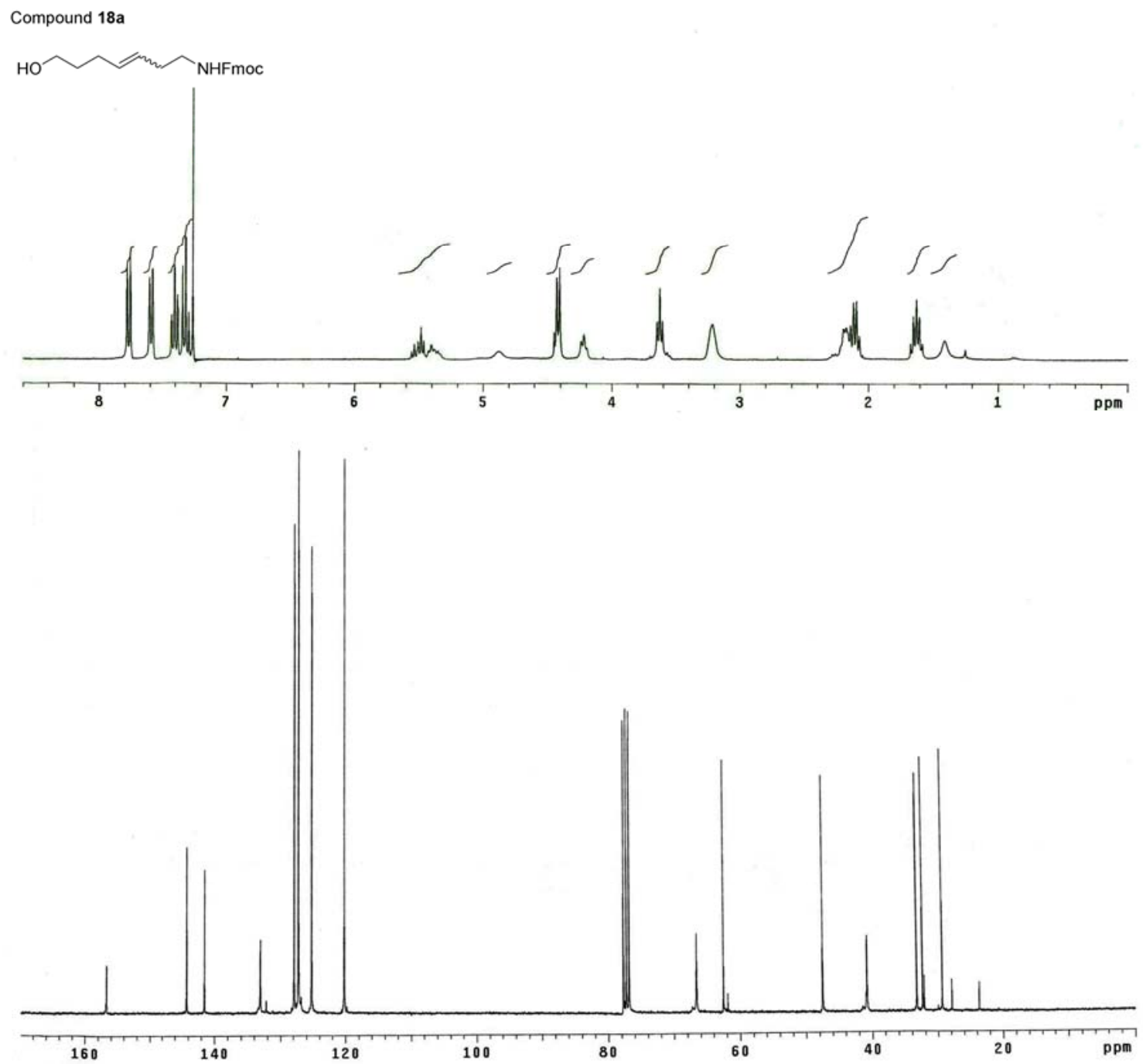


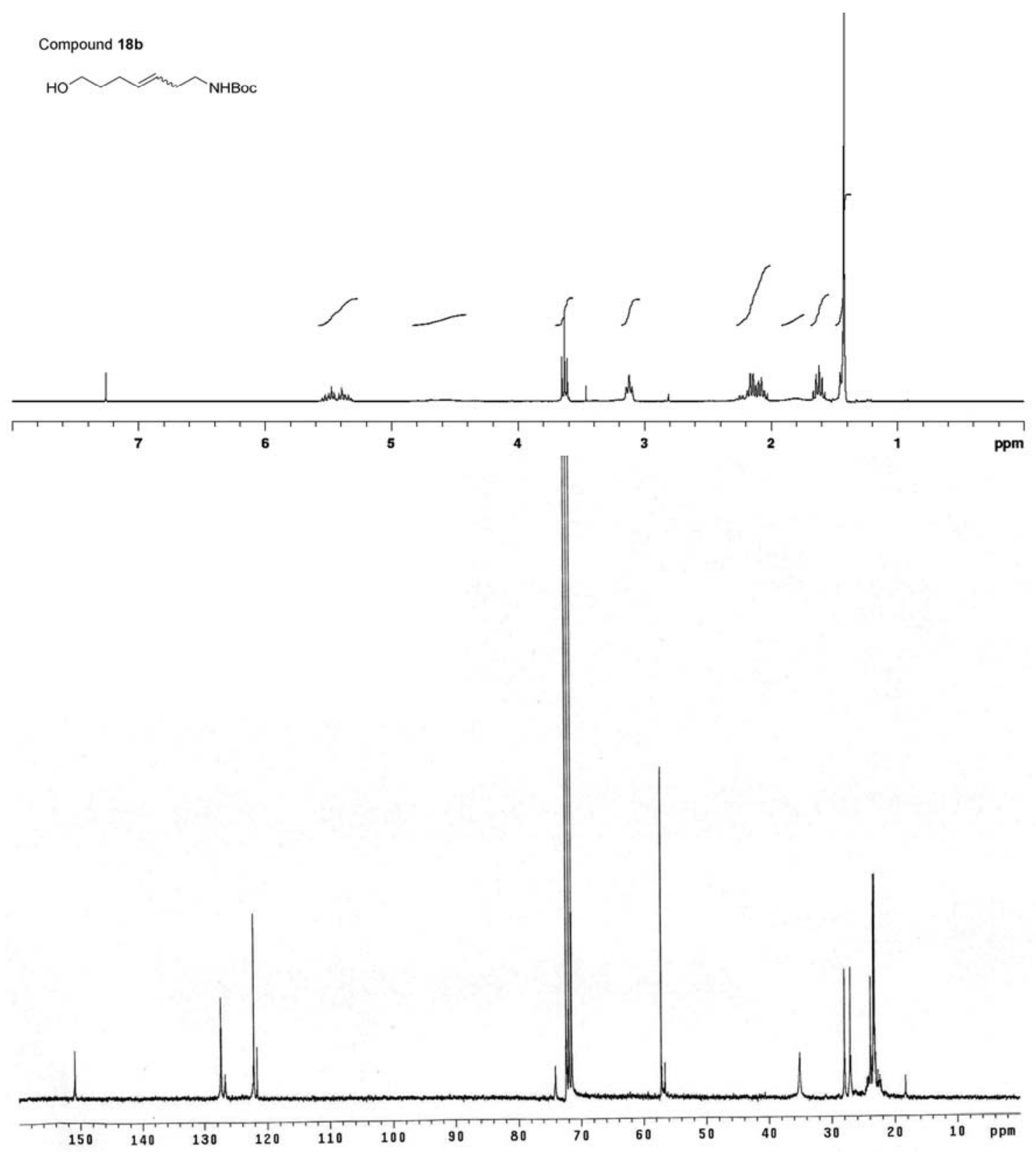

